\title{
GESTÃO DE ORGANIZAÇÕES CULTURAIS E IDENTIDADE TERRITORIAL: A EXPERIÊNCIA DOS PARQUES BIBLIOTECA DE MEDELLÍN E SUAS REPERCUSSÕES 1
}

\author{
MANAGEMENT OF CULTURAL ORGANIZATIONS AND TERRITORIAL IDENTITY: THE EXPERIENCE OF \\ LIBRARY PARKS IN MEDELLIN AND THEIR REPERCUSSIONS
}

GESTIÓN DE ORGANIZACIONES CULTURALES E IDENTIDAD TERRITORIAL: LA EXPERIENCIA DE LOS PARQUES BIBLIOTECA DE MEDELLÍN Y SUS REPERCUSIONES

\author{
FABIANA PIMENTEL SANTOS \\ Doutoranda \\ Universidade Federal da Bahia - Brasil \\ fabianapimentel8@gmail.com \\ ORCID: https://orcid.org/0000-0002-2160-7536 \\ EDUARDO DAVEL \\ Ph.D. \\ Universidade Federal da Bahia - Brasil \\ davel.eduardo@gmail.com \\ ORCID: https://orcid.org/0000-0003-0610-6474
}

Submetido em: 20/03/2017

Aprovado em: 11/04/2018

Doi: alcance.v25n2(Mai/Ago).p240-258

\section{RESUMO}

O objetivo educacional do caso é gerar reflexão sobre os benefícios organizacionais, interorganizacionais e territoriais alcançados ao adotar-se práticas de gestão de equipamentos culturais que tenham como alicerce as originalidades identitárias dos territórios nos quais atuam. Neste caso, em meio a protestos da classe cultural contra ações do recém-empossado prefeito de Sucupira; Godofredo de Assis, assessor-chefe da Secretaria de Cultura, é enviado a Medellín para conhecer as políticas públicas para equipamentos culturais daquela cidade colombiana. Sua missão é obter subsídios para elaborar um plano de ação da Secretaria para os equipamentos culturais da cidade. $O$ caso pretende contribuir para a qualificação de gestores de equipamentos culturais, bem como para a formação de produtores culturais, administradores e gestores sociais.

Palavras-chave: Gestão cultural. Equipamento cultural. Identidade territorial. Caso para ensino.

\footnotetext{
${ }^{1}$ Esse caso para ensino apresenta personagens e lugares fictícios, mas se fundamenta em dados empíricos oriundos de um estudo de caso realizado junto a organizações culturais de Medellín. Os dados foram colhidos a partir de entrevistas, análise documental e observação direta. Algumas pesquisas contribuíram na contextualização do caso, como Bravo (2008), Melguizo (2012) e Roser (2009). A análise de conteúdo desses dados gerou a substância e a estrutura do presente caso de ensino, bem como suas notas de ensino.
} 


\begin{abstract}
The educational goal of this paper is to generate reflection on the organizational, inter-organizational and territorial benefits achieved by adopting identity originality of territories in which cultural facilities operate as the foundation of their management practices. In this case, amidst the protests of the cultural class against the actions of the newly elected mayor of Sucupira, Godofredo de Assis, chief advisor of the Department of Culture, he was sent to Medellin in Columbia, to learn about the public policies for cultural facilities of that city. His mission was to gather information that would be used to draw up an action plan for the cultural facilities of Sucupira. The paper aims to contribute to the qualification of cultural facilities managers, as well as the education of cultural producers, administrators and social managers.
\end{abstract}

Key-words: Cultural management. Cultural facility. Territorial identity. Teaching case.

\title{
RESUMEN
}

El objetivo educacional del caso de estudio es generar una reflexión acerca de los beneficios organizacionales, interorganizacionales y territoriales alcanzados al adoptarse prácticas de gestión de equipamientos culturales que tengan como base las originalidades identitarias de los territorios en los cuales actúan. En este caso de estudio, en medio a protestos de la clase cultural en contra a las acciones del recién empozado alcalde de Sucupira, Godofredo de Assis, asesor-jefe de la Secretaria de Cultura, va a Medellín para conocer a las políticas públicas para equipamientos culturales de aquella ciudad colombiana. Su misión es obtener subsidios para elaborar el plan de acción de la secretaria para los equipamientos culturales de la ciudad. El caso pretende contribuir para la calificación de gestores de equipamientos culturales, así como para la formación de productores culturales, administradores y gestores sociales.

Palabras clave: Gestión cultural. Equipamientos culturales. Identidad territorial. Caso de estudio.

\section{CASO PARA ENSINO}

\section{SUCUPIRA EM TEMPO DE "INOVAÇÃO E DESENVOLVIMENTO"}

Janeiro é mesmo um mês azul em Sucupira. $O$ céu fica absolutamente sem nuvens e o calor é tanto que parece segurar um pouco os ponteiros do relógio. Nem a brisa da noite ameniza a temperatura. Mas, neste janeiro, a cidade está ainda mais quente. Dirceu Amoroso, prefeito recém-empossado, enfrenta a primeira crise de sua gestão. Na calada da noite, um grupo de 50 pessoas, composto de artistas, líderes comunitários, estudantes e professores universitários, ocupou o salão principal do antigo solar que abriga a Prefeitura. Qual não foi a surpresa do prefeito ao chegar logo cedo para trabalhar:

-Que bagunça é essa? - bradou sem medir as palavras, se arrependendo no instante seguinte.

Altino das Cordas, cantador conhecido nas ruas de Sucupira, se apressou em explicar:

- Bagunça não, 'otoridade'

Isso aqui é ocupação!

Sem agenda pra 'audiênça',

'Resolvemo' a questão:

'Viemo' aqui pessoalmente

Demonstrar indignação.

Um parêntese importante: os protestos foram a tônica das eleições. Amoroso fora eleito em um segundo turno apertado, em uma coligação um tanto inusitada, pondo fim a quase duas décadas de governo de um mesmo grupo político. "Inovação e desenvolvimento" havia sido o lema da campanha, marcando um discurso que contrapunha o "jeito velho de governar" do grupo, até então, no poder, ao "novo jeito de governar" da coligação 
encabeçada por ele. Entre as novidades propaladas, estava expandir os horizontes econômicos da cidade, cuja base, desde 0 início do século XX, eram grandes plantações de algodão e tecelagens de pequeno e médio porte. A proposta é inserir Sucupira no segmento da moda e do turismo, aproveitando a tradição têxtil e o extenso litoral da cidade. Durante a campanha, o termo "Economia Criativa" foi ouvido incontáveis vezes, ainda que ninguém entendesse ao certo do que se tratava. Talvez para elucidar esse mistério, o Professor Abelardo de Athayde, coordenador do curso de Letras da universidade local e figura reconhecida na cidade por defender a história e a cultura sucupirense, havia sido nomeado para a recém-criada Secretaria Municipal de Cultura. Segundo o emérito professor, a criação da pasta daria prova inconteste da importância da cultura para pavimentar a entrada de Sucupira no século XXI. Fecha parêntese.

Praticamente arrancado do meio dos manifestantes por seu chefe de gabinete, o prefeito foi conduzido até a sala de reuniões, onde já o esperam seus secretários e assessores. Ao avistar o Professor Abelardo entre os presentes, Amoroso lançou-lhe um olhar fuzilante:

- Professor, o que esses desocupados estão fazendo aqui? Eu exijo uma explicação!

Em tom pedagógico, o professor procurou explicar:

- Prefeito, não são desocupados... São representantes da classe artística da nossa cidade que protestam contra a demolição do antigo curtume para construção do Grand Teatro de Sucupira. Eu conversei com o grupo ao longo da madrugada. Acho importante ouvi-los.

O secretário da Fazenda se apressou a dar sua opinião:

- Quem pode ser contra uma obra desse porte? 0 teatro é fundamental para entrarmos no cenário turístico do Estado. Turístico qualificado, cultural, eu diria! Imaginem quanto empregos serão gerados, quanto de impostos, arrecadaremos... Já temos patrocinador certo para nosso Festival de Inverno!

- Só falta o inverno... - pensou alto Godofredo de Assis, assessor do Professor Abelardo, sendo repreendido pelos olhares de todos.

O emérito professor procurou emendar rapidamente:

- O grupo protesta porque considera que o antigo curtume tem uma história para a cidade e ela não está sendo respeitada pelo projeto do Grand Teatro. Além disso, questionam por que há verba para o "OVNl", como chamam o novo teatro, e não há verba para qualificar os quatro Centros Culturais da prefeitura, localizados na periferia da cidade. Eles reclamam que o pouco que chega lá são umas oficinas que não interessam a ninguém, que não há diálogo com a comunidade, que os Centros não recebem o que a comunidade cria. Nada que eu já não tenha colocado aqui! Eu, inclusive, sugeri que o prefeito recebesse a classe para uma audiência.

Ainda sem conseguir compreender a questão, o prefeito colocou:

- Eu sei, eu sei... Mas, não é cultura que eles querem? Então, o que são quatro centrinhos de bairro frente a um teatro de verdade para receber artistas consagrados? Poderemos receber até ópera! Vejam bem! Se o problema é medo do valor do ingresso, fazemos um programa de acesso. Como é mesmo que vocês chamam? Formação de plateia, não é isso? Está vendo, professor, eu estou aprendendo...

- Sem dúvida, prefeito, será maravilhoso termos um equipamento profissional na nossa cidade. Mas, os Centros também cumprem sua função. Muitos grupos comunitários reclamam, porque não têm espaço para suas atividades. Já os usuários pedem um lugar para o lazer, para um programa em família, para o encontro.

Agora foi a vez do secretário da Saúde pensar alto, porém sem olhares repressores:

- Passeia no shopping. Divirtam-se na praia, ora! Encontro para quê? Para fazer bagunça? 
A certa altura, notando o desconforto do ilustre professor, disparou o Prefeito Dirceu, que lá bem no fundo, concordava com os demais secretários. Mas respeitava a visão de Abelardo.

- Professor, tem muitas questões em jogo. Eu não posso começar minha gestão com impopularidade. Então, vou lhe fazer um desafio. Você tem 60 dias para nos apresentar um plano de ação para os equipamentos culturais de nossa cidade. Agora, resolva a situação com esse povo que está aí fora, antes que chegue a imprensa. Vamos!

\section{A EXPERIÊNCIA DE UM GESTOR CULTURAL: DE SUCUPIRA PARA MEDELLÍN}

Surpreso com a oportunidade que se abria, o professor saiu imediatamente da sala acompanhado de seu assessor, Godô, como era mais conhecido na cidade. Após comunicar o ocorrido aos manifestantes, comprometeu-se com todos a, no prazo máximo de 60 dias, apresentar uma proposta de ação que abarque a questão dos equipamentos culturais da cidade em suas múltiplas interfaces e potencialidades. Mas, passado 0 susto, Abelardo e Godofredo se olhavam sem saber por onde começar.

Então, decidiram fazer uma pesquisa. Primeiro, buscaram experiências brasileiras e se deram conta da escassez de políticas públicas voltadas, especificamente, para o segmento dos equipamentos culturais. $O$ maior destaque foi o Programa Pontos de Cultura², que culminou com a aprovação da Lei Cultura Viva ${ }^{3}$. Sobre o que apuraram, Godô comentou:

- Interessante. Mas, pelo que entendi, seu foco é potencializar uma rede invisível de espaços, muitas vezes, informais, voltada às práticas culturais. Não responde à nossa situação nem à nossa necessidade...

- Sem dúvida. É curioso. Antes de existirem, esses espaços já existiam... Já os nossos equipamentos existem, mas não existem... - filosofou o Professor Abelardo com os olhos perdidos no nada.

- Não entendi, professor.

- Essa política pública ativou pontos que já pulsavam, estavam vivos. Já existiam, entende? Mesmo que as políticas públicas não os enxergassem. Aqui, estamos falando exatamente do oposto. Equipamentos que existem, no caso dos centros comunitários, ou que estão em vias de existir, como o Grand Teatro, mas que não existem de fato para a população. não?

- Entendi agora... Mas, por que os de lá, mesmo num contexto de tantas dificuldades, pulsam e os daqui

- Você percebeu, Godô, o forte vínculo que as experiências dos pontos de cultura estabelecem com seus territórios? Tenho a impressão que essa é a solução de nosso problema!

A dupla seguiu nessa trilha, até chegar às experiências de políticas públicas para equipamentos culturais da Colômbia. $O$ destaque foi para a cidade de Medellín e seus Parques Biblioteca.

- É isso! Precisamos conhecer de perto essa experiência! - falou efusivo o Professor Abelardo, ainda sem saber como convencer o prefeito a fazer este inusitado investimento.

Algumas horas depois, do gabinete do prefeito, ouviu-se um berro:

- Medellín? Vocês enlouqueceram? Eu peço solução e vocês vem com essa!

Ainda que a dupla se esforçasse para explicar o porquê de conhecer de perto a experiência colombiana; apesar de defender que o país havia passado por significativas mudanças desde o final da década de 1990; que Brasil e Colômbia compartilham similaridades históricas, culturais e sociais; nada parecia convencer o prefeito

\footnotetext{
2 Programa Pontos de Cultura: <http://www.cultura.gov.br/documents/10883/12916/portaria-156-de-2004.pdf/2389bd2c-52f9-409f-930904e8890e0946>

${ }^{3}$ Lei Cultura Viva: <http://www.planalto.gov.br/ccivil_03/_ato2011-2014/2014//ei//13018.htm>
} 
daquela ideia. Mas bastou a intervenção do Assessor de Comunicação que casualmente acompanhava a reunião e tudo mudou:

- Prefeito, se me permite. Considero interessante a proposta do ilustre professor. "A nova administração da histórica cidade de Sucupira faz um "benchmark" com políticas culturais do exterior". Boa manchete, não acha? Ainda que este exterior seja um país vizinho, a grande mídia da capital, certamente, se interessará pelo fato. Assim, já vamos projetando seu nome, pensando lá na frente, no Governo de Estado.

O termo anglo-saxão, somados à "grande mídia", "capital" e, principalmente, "Governo do Estado" foram argumentos que dissiparam, instantaneamente, todas as resistências do prefeito.

- Se é assim, vocês têm carta branca! Já estou vendo a manchete...

Impedido pelas demandas necessárias à criação da nova pasta da cultura, o Secretário não podia fazer, ele mesmo, a visita à Colômbia. Assim, coube a Godô a importante missão. Após três semanas de preparação, envolvendo contato com órgãos públicos e entidades culturais de Medellín, Godofredo decolava com destino à capital da Antioquia, onde passaria dois dias.

Entre tantas descobertas que Godofredo realizaria durante aqueles dias, a primeira se apresentou logo no voo. Era a Amazônia! Era a primeira vez que ele sobrevoava aquele mar verde escuro, entrecortado por rios castanhos, que se estendiam como veias de grande calibre, no coração do continente. "Veias abertas", pensou ele, lembrando-se do jornalista e escritor uruguaio Eduardo Galeano, grande apaixonado pela América Latina. Além da Floresta Amazônica, que cobre boa parte do território colombiano, o país ostenta paisagens naturais que vão desde praias no litoral do Pacífico, passando por uma costa caribenha, banhada pelo Oceano Atlântico, até a Cordilheira dos Andes. Era o que havia apurado, Godofredo.

Do ponto de vista étnico, o país é formado por um sem fim de etnias indígenas autóctones, com línguas e tradições culturais variadíssimas, por descendentes dos colonizadores espanhóis e por descendentes de negros, trazidos da África na condição de escravos. No aspecto político, o país é, historicamente, marcado pela figura heroica do revolucionário venezuelano Simón Bolívar, uma vez que foi a última região do então território espanhol da "Nueva Granada", libertado por ele. Mais recentemente, a Colômbia viu sua história política marcada pelo poder do narcotráfico, envolvendo o país num clima de instabilidade e violência. Esse clima começa a mudar a partir de meados da década de 1990. Atualmente, o país é visto como uma potência cultural e econômica dentro do continente latino-americano. No campo artístico, Godofredo tinha como referências o realismo mágico da literatura de Gabriel Garcia Marques e as volumosas figuras do pintor e escultor Fernando Botero, com suas proporções distorcidas a Ihes conferir certo toque de humor. Enquanto sonhava estar sendo abraçado por uma dessas colossais figuras, Godofredo foi surpreendido pela freada do avião, aterrissando. Finalmente, Medellín!

Ao desembarcar, se surpreende com o fato de que há $360^{\circ}$ de montanha ao redor da cidade que está encravada no fundo de um profundo vale. Se alegra com o céu azul e com as temperaturas altas. Muito longe da imagem que estigmatiza a cidade, ele não identificou nenhuma expressão de violência urbana, além do trânsito caótico. Aqui e ali, irrompem a paisagem, modernos e imponentes equipamentos públicos, sempre seguindo a articulada malha viária do metrô, recém-implantado na cidade.

Depois de passar pelo hotel e deixar a mala, Godofredo foi ao único passeio turístico que coube em sua apertada agenda, o Museo de Antioquia4. Principal museu da cidade, localizado no Palacio Municipal, prédio histórico do centro da cidade que se articula com a Plaza Botero, conjunto a céu aberto de 23 esculturas monumentais em bronze do artista local, mais conhecido no mundo (Figura 1).

\footnotetext{
${ }^{4}$ Museo de Antioquia: https://www.museodeantioquia.co/
}

Revista Alcance - Eletrônica - vol. 25 - n. 2 - Mai./Ago. 2018 


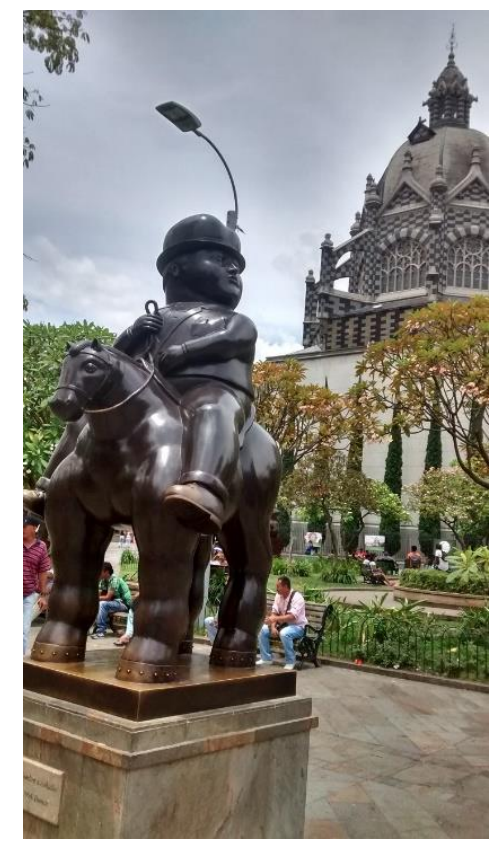

Figura 1: Escultura "Hombre a caballo" de Fernando Botero, como Museo de Antioquia ao fundo Fonte: Dados da Pesquisa (2016).

- Poderia abrir a mochila, Senhor? - falou simpaticamente uma segurança na entrada do museu.

Após mostrar o conteúdo da mochila, Godofredo teve que passar por um detector de metais. Só, então, pôde acessar as dependências, quase vazias, do equipamento. Após uma visita às principais salas de exposição, sentou-se para sua primeira refeição em solo colombiano. Queria um prato típico.

- Vejo que é brasileiro, acertei? Sem dúvida, vai gostar da bandeja paisa5!

Tinha razão: gostou mesmo. Para surpresa de Godô, o prato parecia um belo PF, bem brasileiro. Tinha uma espécie de torresmo gigante, que os colombianos chamam de "chicarrón", um ovo frito, carne moída, arroz, feijão, banana, abacate e uma "arepa"6. Uma delícia! Quando estava pagando a conta, decidiu matar a curiosidade perguntando ao garçom:

- Amigo, até agora não entendi. 0 acervo desse museu é tão especial assim que precisa de todo aquele aparato de segurança na entrada?

Sério e um tanto constrangido, o garçom respondeu:

- Na verdade, Senhor, temos um triste histórico de bombas no país. Sendo assim, verá que muitos prédios de grande circulação adotam este tipo de precaução.

Ao sair do museu, Godô sentiu o contraste entre o silêncio quase monástico do equipamento e a vitalidade do centro de Medellín. Era hora de ir para o hotel e se preparar para as visitas do próximo dia.

\section{CONHECENDO DE PERTO A EXPERIÊNCIA DOS PARQUES BIBLIOTECA}

No dia seguinte, logo cedo, Godofredo foi de metrô até sua primeira reunião. Catalina Velez, gestora do Parque Biblioteca Belém (Figura 2), o receberia para uma entrevista e visita guiada ao equipamento. Como chegou

\footnotetext{
5 Prato mais tradicional da culinária da província de Antioquia.

${ }^{6}$ Alimento feito de massa de milho moído, muito popular e tradicional na Colômbia, Panamá e Venezuela.
} 
com quase uma hora de antecedência, teve tempo suficiente para observar o movimento do lugar. A primeira surpresa: nada de detectores de metais ou revista. 0 prédio ocupava todo um quarteirão, atravessando de uma rua a outra sem portões ou grades (Figura 3).

As pessoas transitavam livremente por seus jardins e pátios, como se eles fossem uma extensão da rua. No centro, um espelho d'água refrescava o ambiente e convidava à contemplação.

- Um lugar para estar! - pensou Godofredo.

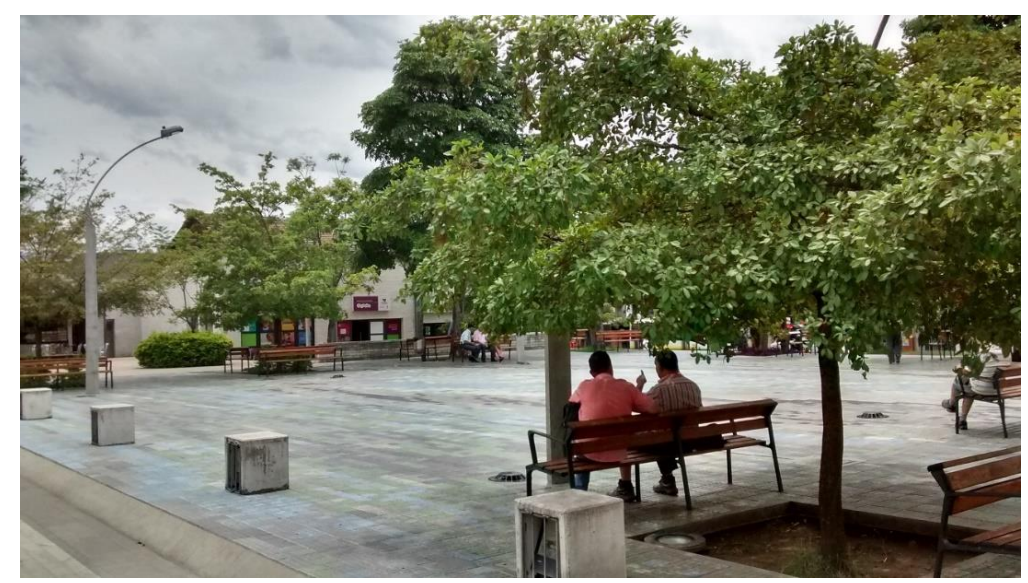

Figura 2: Visão do Pátio Externo na Entrada do Parque Biblioteca Belém Fonte: Dados da Pesquisa (2016).

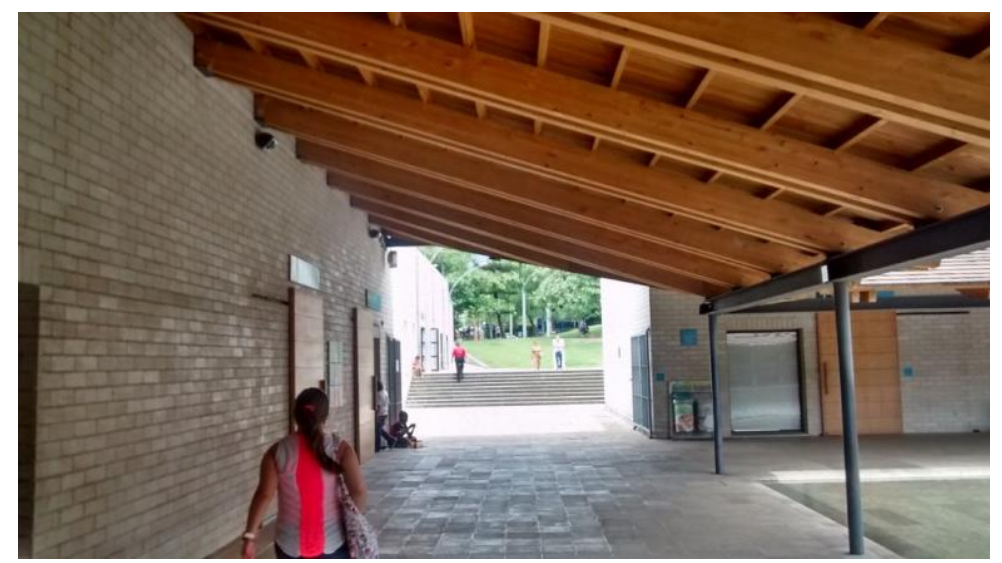

Figura 3: Visão Interna com Vista para o Jardim Externo aos Fundos do Parque Biblioteca Belém Fonte: Dados da Pesquisa (2016).

Passeando um pouco mais, viu nos murais, além da diversa programação da biblioteca, anúncios de todo tipo: apresentações culturais de outros equipamentos da cidade, reunião da Associação de Moradores, classificados de emprego, campanhas de vacinação, oficinas de capacitação profissional... Além disso, percebeu que faziam parte do equipamento um teatro, salas de jogos, salas de ensaio, espaço creche e postos de atendimento de diversos órgãos públicos.

No horário combinado, procurou a recepção. Só então se lembrou de que estava em uma biblioteca. Viu as amplas salas de leitura e o significativo acervo de livros disponíveis à população. Em alguns minutos, Catalina veio encontrá-lo com o sorriso e a cordialidade tipicamente colombianos.

- Olá, Godofredo, sou Catalina. Bem-vindo ao Parque Biblioteca Belém! Como foi a viagem?

- Muito bem, obrigado. Estou aqui encantado com este espaço. Que maravilha! 
- O Parque Biblioteca Belém integra um conjunto de cinco parques biblioteca, espalhados pela periferia de Medellín. O projeto nasceu em 2004 como parte de uma estratégia da prefeitura para promover a convivência cidadã como antídoto à violência urbana.

- Interessante! Então, não foi um projeto da Secretaria Municipal de Cultura? Imaginava que eles tinham a ver como promoção do acesso à cultura.

- Os Parques fazem parte de um conjunto amplo de ações que compunham o Plano de Desenvolvimento da cidade para o período 2004-2007, portanto integram uma ação transversal da Prefeitura que envolveu principalmente as pastas da Educação, da Cultura e da Infraestrutura. A promoção cultural é uma de nossas preocupações, assim como a promoção de atividades comunitárias que ajudem a fortalecer a convivência e a identidade das comunidades.

- Como é a relação do Parque Biblioteca Belém com a comunidade do entorno? Os moradores são frequentadores assíduos?

- Há uma preocupação grande neste sentido. Por exemplo, nosso horário de funcionamento vai até a noite. Não fechamos nos finais de semana. Só temos dois feriados ao longo do ano. Mas eu diria que a comunidade é mais que frequentadora. Ela tem um papel muito ativo em tudo que acontece aqui. Ela é parte da gestão da biblioteca. Vamos à Sala mi Barrio que eu Ihe explico melhor.

Catalina, então, conduziu Godofredo a uma ampla sala com alguns computadores. Era uma mesa de reunião numa confortável área de leitura e algumas estantes com livros. Em tom orgulhoso, ela explicou:

- Esta é a Sala mi Barrio, um espaço que existe em todos os Parques Biblioteca. Eles são centros de memória e documentação comunitários. São geridos pela própria comunidade. Eles derivam das mesas de trabalho realizadas com as lideranças locais, ainda na fase de estudo para a implantação do equipamento.

- Nossa, tudo que está aqui se refere a este bairro, especificamente? - pergunta Godofredo surpreso.

- Exatamente! - responde Catalina, expressando orgulho - São os próprios moradores que se envolvem no processo de registrar a memória e as características do seu bairro. Aqui, eles mapeiam interesses e necessidades da comunidade que precisam ser contempladas pela programação de oficinas e apresentações culturais, oferecidas aqui. Desenvolvem, ainda, atividades como palestras e encontros para debater as questões locais. Esta semana, por exemplo, como estamos em período eleitoral, terão um encontro com um dos candidatos a prefeito.

Cada vez mais interessado, segue Godô:

- Você disse que esse envolvimento comunitário se deu desde antes da construção. Como assim?

- Bom, decidiu-se que seria interessante construir um dos Parques aqui no bairro do Belém. A partir disso, houve uma sensibilização da comunidade que participou, ativamente, de diversas decisões, inclusive arquitetônicas. Por exemplo, inicialmente, nosso teatro teria apenas 200 lugares. Mas a comunidade argumentou que seria insuficiente para a demanda gerada pelas apresentações dos próprios grupos locais. Com isso, 0 arquiteto japonês Hiroshi Naito, contratado para fazer o projeto, teve que rever este ponto. Assim, nosso teatro tem capacidade para 315 pessoas.

- Mas a comunidade também tem acesso a apresentações de artistas consagrados? Ou a programação é estritamente comunitária?

-O Parque Biblioteca é um ponto de encontro entre a comunidade e expressões artísticas e culturais das mais diversas, sejam produzidas ou não pela comunidade. É um ponto de encontro entre a comunidade e diversas formas de conhecimento: educacional, profissional, técnico, cidadão, artístico.... que mais importa aqui é a cultura do encontro, sem barreiras.

Ainda com aquelas palavras na cabeça, Godofredo seguiu para a sua segunda visita do dia no Parque Biblioteca La Ladera (Figura 4). Lá, seria recebido pela gestora Marta Restrepo. 


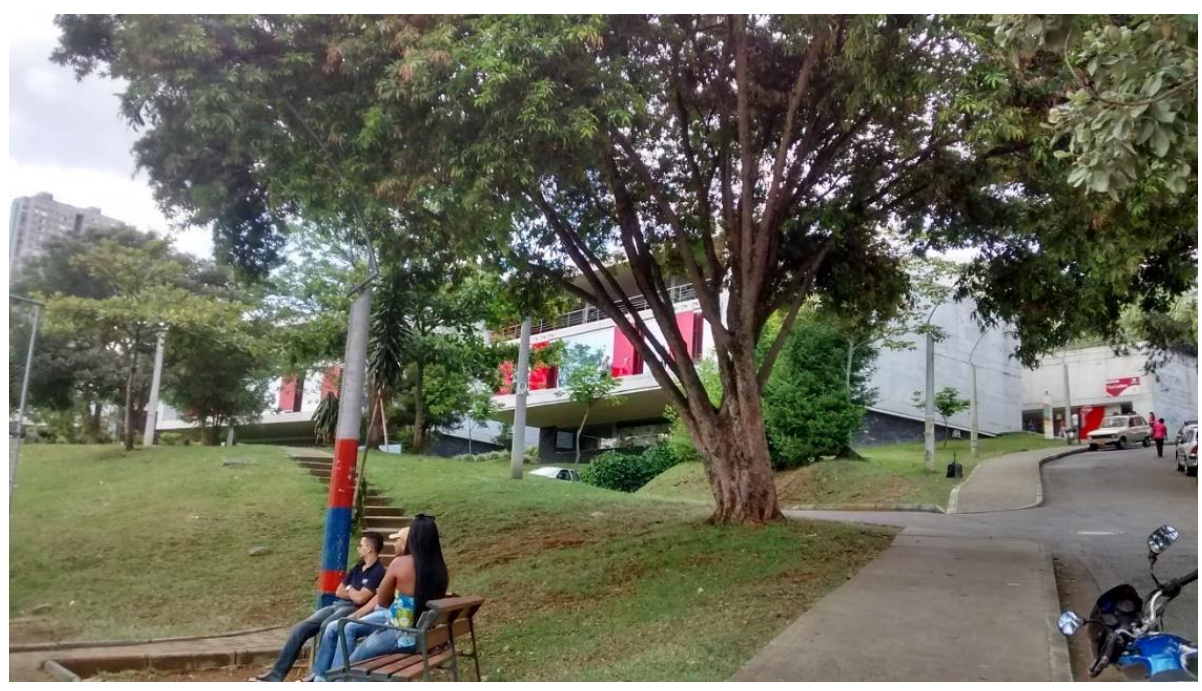

Figura 4: Visão Externa da Entrada do Parque Biblioteca La Ladera Fonte: Dados da Pesquisa (2016).

Já na entrada do edifício, Ihe chamou a atenção uma grande maquete que parecia mapear a comunidade. Enquanto tentava entender do que se tratava, Marta se apresentou:

- Olá, sou Marta... Você deve ser meu amigo brasileiro. Estou certa?

- Sim, muito prazer, Godofredo de Assis. Muito obrigado por me receber! Estou aqui admirando essa maquete. Trata-se da comunidade onde estamos?

- Exatamente! - disse Marta. Essa é uma história muito interessante. Ano passado, um departamento da prefeitura esteve aqui para fazer um mapeamento territorial. Trabalharam alguns meses, depois apresentaram à comunidade o mapeamento que produziram. Mas a comunidade não se enxergou no que viu e decidiu ela mesma fazer o seu mapeamento territorial para apresentar à prefeitura. Deste esforço coletivo, nasceram um documento, essa maquete e uma exposição de fotografias que foi exibida aqui no Parque Biblioteca La Ladera.

Visivelmente surpreso e encantando, Godofredo seguiu:

- Nossa! Qual foi o papel da Biblioteca nesta mobilização?

- A Biblioteca é um ponto de encontro para a comunidade. Sei que esteve em Belém mais cedo e deve ter conhecido a Sala Mi Barrio. Aqui, também, temos a nossa e a comunidade é muito atuante devido à própria história do bairro. A partir dessa mobilização independente, o que fizemos como espaço cultural foi estimulá-los a explorarem a dimensão expressiva da ação. Com isso, nasceu a exposição. 0 mapeamento nos ajudou a entender melhor as dinâmicas do território para pensar um equipamento cada vez mais relevante que responda às demandas do entorno. Mas que, ao mesmo tempo, provoque e ajude a expansão de horizontes, estimule a reflexão, a aquisição de valores de convivência.

- Vejo que estamos em uma zona bastante vulnerável da cidade, não é mesmo? O que há de peculiar na história desse lugar?

- Anos atrás, aqui funcionava um presídio. Muito do que se construiu em volta e das histórias que marcam esse lugar partem desse passado triste. A própria imagem que a cidade tem desta zona sempre esteve associada a este aspecto. A construção do Parque Biblioteca tinha o propósito, dentre tantos outros, de ressignificar esse lugar, substituindo esse estigma por um conjunto de novas possibilidades. Com isso, novas relações foram surgindo e uma nova imagem da comunidade foi se desenvolvendo.

Godofredo sorriu. Era muita informação para processar. A visita seguiu pelas dependências do lindo edifício (Figura 5). Eram salas de leitura com acervo e programação voltada a públicos específicos; espaços de 
estudo e pesquisa equipados com computadores conectados à Internet; espaço creche; um pequeno, mas bem equipado, teatro; salas para ensaios e oficinas; espaço expositivo e cafeteria.

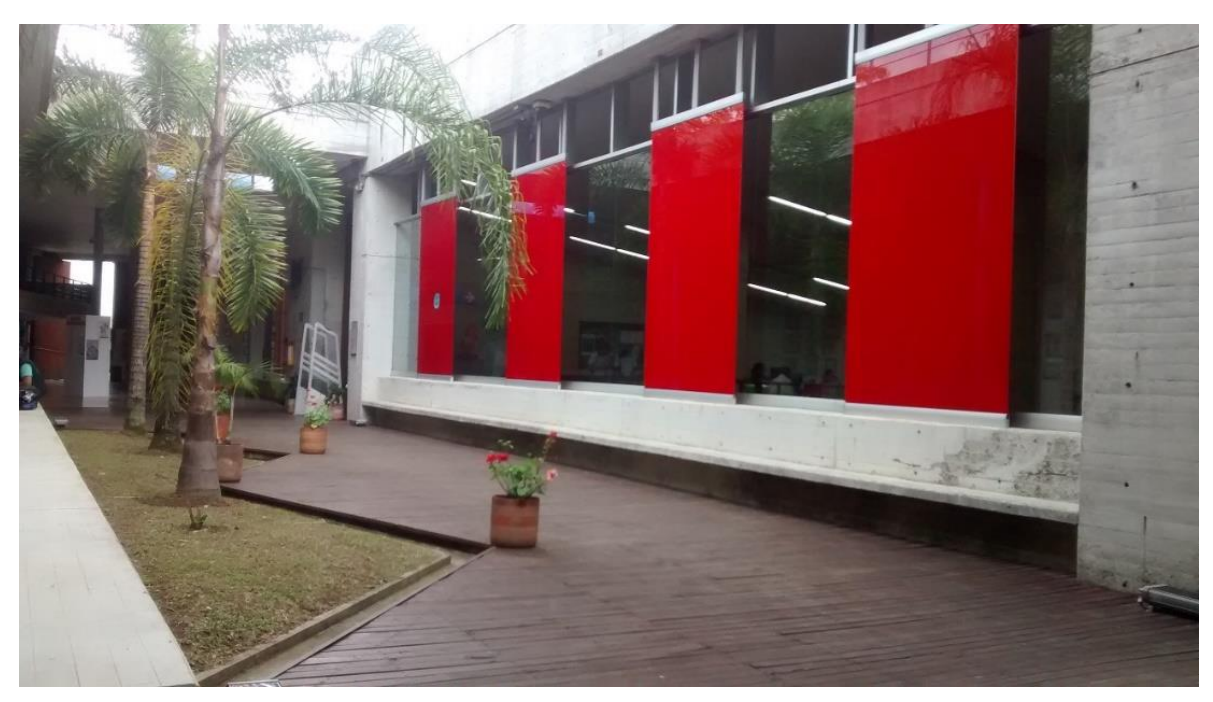

Figura 5: Visão do Pátio Interno do Parque Biblioteca La Ladera Fonte: Dados da Pesquisa (2016).

Ao final, lhe ocorreu outra questão importante:

- Marta, e a sustentabilidade dessa rede de Bibliotecas? Como manter a qualidade e a constância na oferta deste serviço? No Brasil, os orçamentos para a cultura são sempre o primeiro dos desafios que temos que superar.

- Bom, aqui não é diferente. Vivemos uma situação econômica, política e social tipicamente latinoamericana, como vocês. Então, a questão dos recursos econômicos é sempre uma questão. Mas os Parques Bibliotecas são exemplo de um modelo interessante. Trata-se de uma parceria público-privada que envolve três instâncias: a prefeitura, responsável pelo terreno, pela construção, pelas licenças e serviços públicos; entidades privadas sem fins lucrativos ${ }^{7}$, que respondem pela gestão e programação artística dos equipamentos; e a sociedade civil, que participa desde a construção das bibliotecas e segue atuante no cotidiano da gestão, expondo suas demandas e exercendo controle social. Deste modo, a manutenção financeira do programa vem sendo mantida. Já vamos com mais de uma década de trabalho. Penso que um grande fator de sustentabilidade para 0 projeto é que ele não foi pensado apenas na pasta da cultura, mas a partir de um pensamento mais sistêmico que envolveu outras áreas como a social e o desenvolvimento urbano.

Refletindo sobre os desafios da gestão do Parque, Godô indagou a Marta:

- Imagino que são muitos os desafios para gerir um espaço assim, não é mesmo?

- Sem dúvida. Lidamos com um sem fim de coisas! Manutenção do prédio e dos jardins; definição de programação artística e oficinas; gestão e conservação do acervo de livros e periódicos; diversas questões administrativas e trabalhistas. Gerir um equipamento cultural é muito desafiador.

- Entendo, mas falava mesmo da relação com a comunidade.

\footnotetext{
${ }^{7}$ Mais especificamente, fundos de entidades privadas sem fins lucrativos, cuja principal função é arrecadar contribuições dos seus empregados e revertê-las em serviços culturais à população mais carente. No Brasil, teriam um paralelo no Sistema $S$ (SESC, SENAC, SENAI, SESI).
} 
- Olha, eu diria a você que dá trabalho sim, porque há demandas e expectativas frustradas de parte a parte, como em toda relação. Mas esta é a parte mais importante do que fazemos. Caso contrário, teríamos o mesmo trabalho que listei antes, mas não teríamos a sensação de que fazemos sentido para as pessoas, não sei se me entende? Esse contato vivo com nossos usuários é a diferença entre um diálogo e um monólogo, sabe? Um exemplo que está acontecendo neste momento, estamos estudando juntos, gestores e usuários, como integramos os animais de estimação à programação do equipamento. É uma demanda da comunidade bastante desafiadora para nós. Mas estamos tendo que encarar. Não sei no Brasil, mas aqui na Colômbia os "pets" passaram a ser uma extensão da família. Então, como deixar de encarar essa questão? ceticismo:

Ainda que visivelmente maravilhado com a experiência, Godofredo não consegue esconder certo

- Que estimulante pensar a cultura a partir deste prisma! Me pergunto se este tipo de abordagem não seria uma opção restrita a uma feição bem específica de equipamento. Como equipamentos que atuam em uma escala que não seja estritamente comunitária poderiam se espelhar no que você me apresenta? Ou, ainda, equipamentos com acervos históricos, por exemplo, que por si impõem aos gestores certos compromissos e limites?

Sorrindo cordialmente, Marta Ihe faz um convite:

- Como está sua agenda amanhã? Se estiver livre, vou lhe apresentar a alguém que pode ajudar a responder essas perguntas. Agora, vamos brindar esse intercâmbio Brasil-Colômbia com uma das bebidas mais famosas dos nossos países: o café!

Depois de um gostoso café colombiano, Godofredo acertou os detalhes do próximo encontro e se despediu de Marta. Na saída, pegou um folheto com toda a programação dos cinco Parques Biblioteca para ler em algum momento da viagem.

\section{DOS PARQUE BIBLIOTECA PARA TODA A CIDADE DE MEDELLÍN}

Em seu último dia na cidade, Godofredo acordou cedo para uma reunião na Secretaria Municipal de Cultura de Medellín. Lá, um assessor lhe recebeu e fez longa apresentação dos desdobramentos da experiência dos Parques Biblioteca para as políticas públicas da província de Antioquia. Conheceu o Centro de Desarrollo Cultural de Moravia ${ }^{8}$, um grande equipamento cultural erguido em 2005 nas proximidades do antigo aterro sanitário na zona norte da cidade. Herdeiro direto da experiência dos Parque Bibliotecas, o equipamento atua a partir da recuperação da memória local, da promoção do convívio e do estímulo a uma educação cidadã, tendo a cultura e as artes como eixo central e alicerce para os processos de desenvolvimento da comunidade. Conheceu, ainda, o projeto Parques Educativos ${ }^{9}$, iniciativa da Secretaria de Educação de Antioquia, que consiste na implementação de equipamentos multifuncionais (educativos, esportivos e culturais) em 80 cidades da província, tendo como princípios de intervenção e gestão os mesmos moldes dos Parques Biblioteca.

Godofredo saiu da secretaria convencido do sucesso daquela política pública, mas ainda tinha dúvidas quanto aos limites e às possibilidades de adotar a mesma abordagem a outros perfis de equipamentos. Com essas dúvidas na cabeça, chegou ao centro da cidade onde marcou com Marta Restrepo:

- Olá Marta, consegui chegar sem problemas! Estou me sentindo como um local! Como está você?

- Muito bem! Então, preparado para ir à praia?

- Aqui tem praia? Eu pensei que... - Godô ainda tentava entender quando virou a esquina e se surpreendeu com o que avistou do outro lado da rua.

\footnotetext{
${ }^{8}$ Centro de Desarrollo Cultural de Moravia: http://centroculturalmoravia.org/formacion/cursos-de-formacion/

9 Parques educativos: http://www.seduca.gov.co/parques-educativos-de-antioquia/parques-educativos-de-antioquia-80parques-educativos
}

Revista Alcance - Eletrônica - vol. 25 - n. 2 - Mai./Ago. 2018 
Animada Marta seguiu:

- Tcharam!! Tem sim! No Teatro Pablo Tobón Uribe ${ }^{10}$, hoje é dia de praia!

O que se via era um bonito teatro com uma arquitetura que parecia datar dos anos 50 ou $60 \mathrm{com}$ seu pátio frontal coberto de areia, cadeiras de praia e guarda-sóis. A visão, no mínimo inusitada, era de uma praia artificial

\section{Godô não pôde conter o riso:}

- Isso é maravilhoso! Praia sim, por que não?

Sentaram-se em uma cadeira de praia e, enquanto assistiam a uma aula de yoga, Marta lhe contou que aquele era um teatro privado, ícone na cidade e no país, palco de artistas renomados e, durante muito tempo, ponto de encontro da elite da cidade. Porém, ao longo dos anos, mudanças urbanísticas fizeram com que aquela área do centro de Medellín fosse ficando cada vez mais abandonada, com reflexos inevitáveis no dia a dia do teatro. O "Días de Playa"11 foi um projeto artístico criado pelo teatro em 2014, com a finalidade de reatar laços entre 0 equipamento e a cidade, estimulando todos a repensarem o uso do espaço público.

\section{Muito entusiasmado, Godofredo perguntou:}

- Por que toda essa faixa do asfalto pintada de azul (Figura 6)? Vejo que ela se estende para bem longe, fazendo uma espécie de caminho...

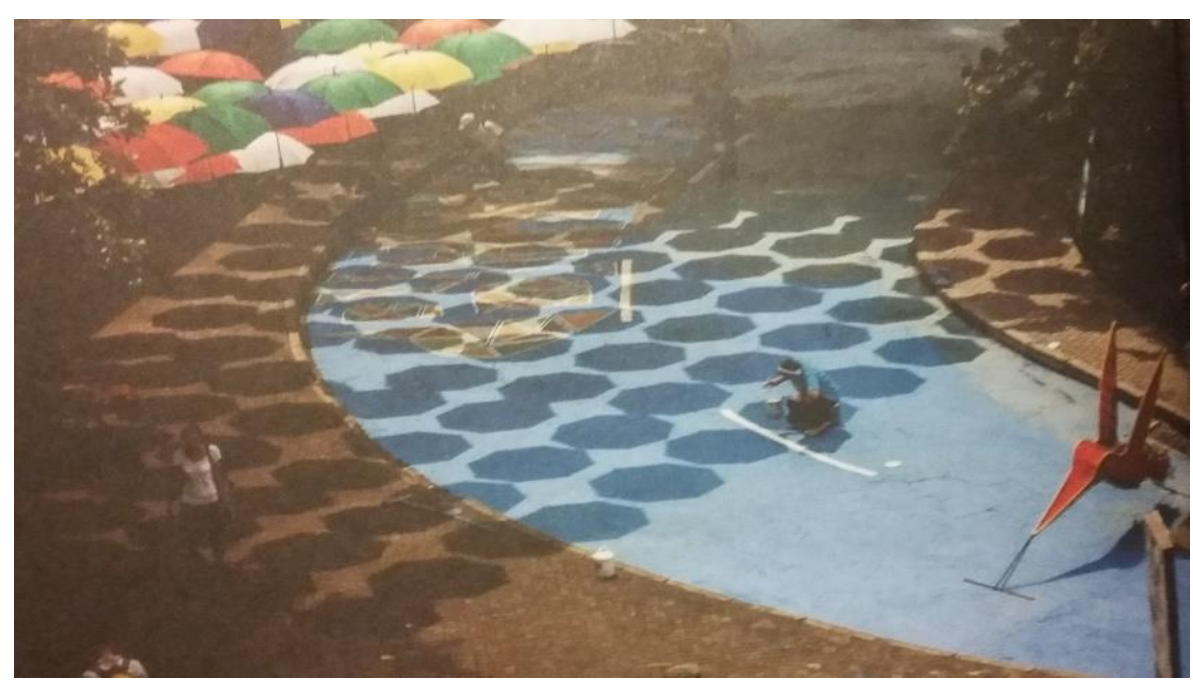

Figura 6: Projeto Dias de Palya

Fonte: Alcaldía De Medellín (2015, p. 84).

Uma voz grave com fala ligeira chegou respondendo:

- É que nossa praia refaz o curso de um riacho que passa por baixo de nossos pés e foi canalizado, tapado, há muitos e muitos anos. Você deve ser o amigo brasileiro. Eu sou Sergio Arenas, diretor do Teatro Pablo Tobón Uribe. Muito prazer!

Sergio, que era amigo de longas datas de Marta e um premiado artista de teatro, explicou que o projeto buscou envolver a comunidade (vizinhos, comerciantes, empresas, etc.) em atividades artístico-culturais estimuladoras de convivência, para assim ativar a memória do lugar e fazer dela uma plataforma para construir

\footnotetext{
10 Teatro Pablo Tobón Uribe: http://www.teatropablotobon.com/

11 Projeto "Días de Playa": http://www.diasdeplaya.com/
} 
novos imaginários sobre o centro. Explica que o movimento cresceu e estava afetando algumas instâncias do poder público.

Completamente à vontade, Godô perguntou a Sergio:

- Ontem Marta disse que me traria aqui porque via correlação entre essa iniciativa de vocês e a política dos Parques Biblioteca. Você diria o mesmo?

Entre o poético e o enigmático, Sergio perguntou:

- Você já atirou uma pedrinha em um lago? Pois bem, por menor que ela seja, seu efeito se propaga em todas as direções. Assim são as ideias. Elas se propagam, repercutindo em muitas direções. Os Parques Biblioteca mostraram que é preciso olhar para fora e trazer o que está fora para dentro. Abrir portas e janelas. Em grande medida, é o que estamos fazendo aqui. Espero que essas ondinhas cheguem até o Brasil!

\section{DE VOLTA A SUCUPIRA E COM MENOS DE 60 DIAS PARA CUMPRIR A MISSÃO}

Havia se passado apenas três dias desde sua saída de Sucupira, mas a intensidade das experiências vividas fazia Godofredo duvidar do tempo. Sentia-se profundamente grato aos paisa ${ }^{12}$ pela acolhida. Era hora de voltar para casa e ajudar o Professor Abelardo a apresentar ao prefeito e à população um plano inovador para os equipamentos culturais da cidade. Em poucos minutos o avião decolaria e ele ainda se esforçava para estabelecer conexões entre tudo aquilo e a realidade brasileira e sucupirense. Se esforçava também para fazer uma análise crítica de tudo o que viu, porque nem tudo são flores. Territórios são arenas de poder, já que as relações que abarcam mexem com interesses diversos e, muitas vezes, conflituosos. Desconfiava da possibilidade de uso eleitoreiro daquela política pública e tinha algumas dúvidas quanto à efetiva participação popular na gestão dos equipamentos. Fora isso, ainda tinha o desafio econômico, já que o modelo de Medellín não se aplicaria à Sucupira.

Subitamente, uma ideia the veio à mente e, para não perdê-la, buscou, apressado, seu caderninho de anotações. Ao fazê-lo, encontrou a programação da rede de Parques Biblioteca que havia pegado em La Ladera, no dia anterior. Parou os olhos justamente nas palavras do argentino Jorge Luis Borges, encontrando assim mais um motivo de inspiração.

\footnotetext{
"Quero dar graças ao Divino

Labirinto dos efeitos e das causas

Pela diversidade das criaturas

Que formam este singular universo,

Pela razão, que não cessará de sonhar

Com um mapa do labirinto,

Pelo rosto de Helena e a perseverança de Ulisses,

Pelo amor que nos deixa ver os outros

Tal como nos vê a divindade"13
}

\footnotetext{
${ }^{12}$ Como são chamados os colombianos nascidos no norte do país.

${ }^{13}$ Fragmento do poema "Otro poema de losdones" de Jorge Luis Borges, publicado pela primeira vez no livro "El otro, elmismo", em 1964. Tradução dos autores.
} 


\section{NOTAS DE ENSINO}

\section{SINOPSE}

Em meio a protestos da classe cultural contra ações do recém-empossado prefeito de Sucupira, Godofredo de Assis, assessor-chefe da Secretaria de Cultura, é enviado a Medellín para conhecer as políticas públicas para equipamentos culturais daquela cidade colombiana. Sua missão é colher subsídios para elaborar um plano de ação da Secretaria para os equipamentos culturais da cidade, de maneira a articular a construção de um teatro de grande porte, voltado à atração de eventos turísticos, com a recuperação de quatro centros comunitários localizados na periferia da cidade. Durante a viagem, ele conhece a experiência colombiana dos Parques Biblioteca e suas estratégias de criação de vínculo entre equipamento e comunidade, a partir da valorização da identidade territorial. Além disso, conhece três experiências inspiradas nos Parques: o Centro de Desarrollo Cultural de Moravia, os Parques Educativos e o projeto Días de Playa, do Teatro Tobón Uribe. Agora, Ihe cabe elaborar, juntamente com o secretário de cultura, Professor Aberlado de Athayde, o referido plano que será apresentado ao prefeito e aos cidadãos da cidade.

\section{OBJETIVOS EDUCACIONAIS}

O caso objetiva contribuir com a qualificação de gestores de equipamentos culturais, bem como para a formação de produtores culturais, administradores e gestores sociais, uma vez que ajuda a:

- Entender o papel estratégico da identidade territorial na gestão de equipamentos culturais.

- Compreender como a identidade territorial reconfigura o papel do equipamento cultural junto a sua comunidade.

- Identificar e discutir impactos organizacionais e interorganizacionais da identidade territorial.

\section{USO PEDAGÓGICO}

Sugere-se como atividade pedagógica para a aplicação do caso para ensino a seguinte sequência de ações que demandarão, no mínimo, três aulas de 50 minutos.

Etapa 1 - Sistematização da Identidade e seus Diversos Benefícios

- Dividir a sala em equipes para leitura do caso para ensino.

- Identificar e discutir, ainda em equipes, as originalidades identitárias dos territórios da cidade de Medellín, apresentadas no caso. Solicitar que cada equipe sistematize sua discussão usando como suporte o quadro abaixo:

\begin{tabular}{|l|l|}
\hline \multicolumn{1}{|c|}{ ASPECTOS TERRITORIAIS } & ELEMENTOS OBSERVADOS NO CASO \\
\hline Paisagem natural & \\
\hline Paisagem urbana & \\
\hline Usos do território & \\
\hline Aspectos históricos & \\
\hline Aspectos sociais, políticos e econômicos & \\
\hline Aspectos simbólicos & \\
\hline
\end{tabular}

- Identificar e discutir, ainda em equipes, os benefícios oriundos das originalidades identitárias, elencadas anteriormente. Solicitar que cada equipe sistematize sua discussão usando como suporte o quadro abaixo:

\begin{tabular}{|c|c|c|}
\hline \multicolumn{3}{|c|}{ QUADRO DE BENEFICIOS } \\
\hline ORGANIZACIONAL & INTERORGANIZACIONAL & TERRITORIAL \\
\hline & & \\
\hline & & \\
\hline
\end{tabular}


- Solicitar que cada equipe apresente seus resultados, integrando as sistematizações realizadas por equipe em dois grandes quadros que sintetizem a visão de toda a turma sobre as originalidades identitárias apresentadas pelo caso e seus benefícios.

\section{Etapa 2: Reflexão Teórica sobre Gestão e Identidade Territorial}

- Leitura do texto de Saquet e Briskievicz (2009) e elaboração, por cada equipe, de uma resposta para a Questão \#1, a ser apresentada para a turma.

- Apresentação das respostas que cada equipe elaborou para a Questão \#1. As discussões podem ser realizadas logo após a apresentação de cada equipe ou no final de todas as apresentações.

- Leitura do texto de Lacerda (2011) e elaboração, por equipe, de uma resposta para a Questão \#2, a ser apresentada para a turma.

- Apresentação das respostas que cada equipe elaborou para a Questão \#2. As discussões podem ser realizadas logo após a apresentação de cada equipe ou no final de todas as apresentações.

- Leitura do texto de Davel et al. (2016) e elaboração, por equipe, de uma resposta para a Questão \#3, a ser apresentada para a turma.

- Apresentação das respostas que cada equipe elaborou para a Questão \#3. As discussões podem ser realizadas logo após a apresentação de cada equipe ou no final de todas as apresentações.

Etapa 3: Integração de Conhecimentos por Meio da Elaboração de um Plano de Ação

- Elaboração, por parte de cada uma das equipes, de um plano de ação para equipamentos culturais a ser apresentado por Godofredo e pelo Prof. Abelardo ao prefeito e aos cidadãos de Sucupira.

- Apresentação do plano de cada equipe. As discussões podem ser realizadas logo após a apresentação de cada equipe ou no final de todas as apresentações.

\section{QUESTÕES PARA DISCUSSÃO}

\section{Questão \#1}

As situações descritas no caso para ensino revelam o poder estratégico da articulação entre gestão cultural, território e identidade. A partir da análise do caso e da leitura de Saquet e Briskievicz (2009), que papel a identidade territorial desempenha na gestão cultural de equipamentos culturais?

\section{Resposta possível}

Os equipamentos culturais observados pelo personagem Godofredo na cidade colombiana de Medellín se caracterizam por uma aproximação dos processos e das práticas de gestão cultural ao binômio identidade e território. Tal abordagem se reflete em benefícios organizacionais (diferenciação da ação destas organizações e maior senso de pertencimento gerado entre seus frequentadores), mas também interorganizacionais (estímulo ao desenvolvimento de ações de cooperação com outras organizações) e territoriais (contribuição à transformação do contexto local) que inserem os equipamentos de forma mais destacada e relevante no contexto social.

O conceito de território apresentado vincula-se a uma concepção político-cultural do seu estudo (Haesbaert, 2004; Santos, 2000; Saquet \& Briskievicz, 2009). Nesta perspectiva, a "base material natural ou construída; as atividades econômicas que são empreendidas; as estruturas sociais que são geradas e suas interrelações; as instituições construídas e as regras do jogo; os valores e os códigos adotados" (Echeverri, 2009, p.25) são elementos constituintes do território, considerado como espaço produzido num processo dinâmico e permanente, que difere em muito do senso comum, que costuma associá-lo a uma ideia de permanência e imutabilidade.

Do mesmo modo, a identidade é vista como socialmente construída e não como uma essência. Sob esta ótica, ela se relaciona com atributos étnicos, culturais, econômicos, políticos, preferências religiosas, políticas, estéticas e sexuais (Echeverri, 2009). É processada individual e coletivamente de forma a reorganizar seu significado a partir de tendências sociais e projetos culturais enraizados e sua estrutura social, bem como em sua visão de espaço-tempo (Castells, 1999). Com base neste entendimento, território e identidade influenciam-se mutuamente, sendo a identidade construída pelas múltiplas relações-territorialidades que são estabelecidas todos 
os dias. Isso envolve, necessariamente, as obras materiais e imateriais que são produzidas (Saquet \& Briskievicz, 2009).

À luz destas concepções, o dinamismo inerente a tais processos não produz uma identidade territorial inequívoca. Mas revela um potencial identitário que varia no tempo e de acordo com o sistema de significados (relações simbólicas) e com a forma de organização do poder (relações políticas) adotados pelos indivíduos.

Neste contexto, as organizações são parte do conjunto de atores sociais que se relacionam no e com 0 território, afetando e sendo afetadas por suas dinâmicas identitárias (Saraiva \& Carrieri, 2014). Corrobora com tal visão o entendimento de que, ao articular um conjunto de ações voltadas a garantir os meios necessários para a criação, difusão, circulação, fruição e preservação de bens e serviços artístico-culturais, a gestão cultural envolve a mediação de diferentes processos e agentes sociais, atuando em um espaço de interação entre o fenômeno cultural e o fenômeno organizacional (Saraiva, 2011). Deste modo, as organizações culturais, cuja própria natureza de ação está vinculada, indissociavelmente, aos trânsitos entre as dimensões material e imaterial, detêm um expressivo potencial de mobilização dos componentes identitários dos territórios nos quais atuam. Dentro deste segmento, tomando mais especificamente os equipamentos culturais (teatros, cinemas, bibliotecas, arquivos, galerias, espaços polivalentes, salas de concerto, museus, centros comunitários, etc.), por sua característica de um espaço edificado inserido, permanentemente, em um dado território, tal potencial de mobilização se intensifica ainda mais, justificando a adoção da identidade territorial como alicerce para a qualificação e inovação das suas práticas gerenciais, conforme exposto pelos exemplos do caso.

Assim como ocorreu com o personagem Godofredo, tal abordagem pode parecer não considerar as peculiaridades de equipamentos que, por exemplo, atuem em diferentes escalas territoriais ou que partam de propostas curatoriais, acervos e interesses temáticos muito específicos que problematizem sua capacidade de diálogo com potencial identitário do seu território de base. Ou, ainda, que por focar nas relações territoriais mais imediatas, tal abordagem parece desconsiderar aspectos flagrantes da pós-modernidade como a compressão do tempo-espaço (Harvey, 2014), "a tensão entre o 'global' e o 'local' na transformação das identidades" (Hall, 2014, p.44) ou o fato de que as pessoas e as organizações se relacionam, simultaneamente, com várias escalas territoriais diferentes, o que Haesbaert (2000) chama de multiterritorialidade.

Contudo, conforme exemplos trazidos pelo caso, a estratégia da territorialização da gestão se propõe aplicável, em diferentes níveis, para as mais variadas feições de equipamentos culturais. $O$ fortalecimento dos vínculos entre o equipamento e seu contexto territorial mais imediato é viável e estratégico para todo e qualquer equipamento. Viável porque seja qual for a vocação, natureza ou escala de atuação, ele sempre parte de uma base territorial. Estratégico porque é uma plataforma para a construção de uma identidade organizacional forte e reconhecível capaz de projetar e/ou fortalecer sua atuação para diferentes escalas territoriais.

\section{Questão \#2}

Adotar a identidade territorial como alicerce da gestão de equipamentos culturais desloca a atenção do gestor, exclusivamente, da ação cultural, voltando-a para as relações territoriais que o equipamento mantém ou pode vir a manter. Com base na análise do caso e na leitura de Lacerda (2011), de que forma os conceitos de democratização cultural e democracia cultural se articulam com este contexto?

\section{Resposta possível}

Historicamente, os equipamentos culturais estão fortemente vinculados à ideia de proteção e/ou distribuição da produção cultural legitimada, o que lhe conferiria uma 'vocação natural' para a "popularização da arte, do conhecimento científico, das formas de 'alta cultura'" (Canedo, 2007), concepção típica dos processos de democratização cultural. As mais remotas referências a este tipo espaço, como a Biblioteca de Alexandria, erguida pelos egípcios no século II a.C., ou os gabinetes de curiosidades dos séculos XVI e XVII, tidos como os antecessores dos museus, espelham estas ideias. Assim como dois acontecimentos ocorridos na França (De Marco, 2009), cujos reflexos tiveram alcance mundial. O primeiro deles diz respeito ao período pós-revolução francesa, caracterizado pelo florescimento dos ideais iluministas de universalização do conhecimento e simbolizado pela criação do Louvre, em 1793. Já o segundo, se refere ao período iniciado em 1950 e caracterizado pela criação das primeiras políticas públicas para a cultura daquele país, estão relacionadas à promoção do acesso aos bens culturais e, consequentemente, voltadas à criação e ao fortalecimento dos equipamentos culturais. 
Símbolo deste segundo momento foi a inauguração do Centro Nacional de Arte e Cultura Georges Pompidou, o "Beaubourg", em 1975.

Contudo, já na década de 1960, ao sistematizar pesquisas de público nos museus franceses, Bourdieu e Darel (2003) problematizam os impactos alcançados pelas políticas de democratização cultural, comprovando que "empreender esforços na diminuição das barreiras físicas entre a cultura erudita e as classes populares" (Lacerda, 2011) não era condição suficiente para aproximar os equipamentos ao público, sobretudo aquele público oriundo de contextos socioeconômicos mais vulneráveis, precisamente a quem este tipo de política pretende atender. Não apenas a existência e a boa distribuição dos equipamentos culturais, nem mesmo a facilitação ao acesso por meio de ingressos a preços populares ou gratuidade garantem que estes espaços se mostrem efetivamente acessíveis, desejados pela população ou capazes de gerar impactos de ordem cultural ou social.

Os reflexos desta abordagem tradicional podem ser notados no caso para ensino, na fala do prefeito $\mathrm{e}$ do secretário da Fazenda de Sucupira. Reaparece na fala de Godofredo ao questionar à gestora o Parque Biblioteca Belém se a população tinha acesso a "artistas consagrados". A ideia de democracia cultural oferece um contraponto a esta visão que, a partir do exemplo francês, se tornou fundamental para a formulação das políticas culturais no mundo inteiro. Ela parte do reconhecimento de que todo ser humano é produtor de cultura e tem por princípio "favorecer a expressão de subculturas particulares e fornecer aos excluídos da cultura tradicional os meios de desenvolvimento para deles mesmos se cultivarem, segundo suas próprias necessidades e exigências" (Botelho, 2001).

O estreitamento dos laços entre os equipamentos e o seu entorno por meio da valorização da identidade territorial, conforme observado nos exemplos presentes no caso, estimulam a aproximação entre estas organizações e o conceito de democracia cultural. Isso demanda o reforço à transversalidade das ações do equipamento e o desenvolvimento de estratégias de escuta e participação da comunidade. A consequência desta atuação de carácter mais interacionista é a mobilização dos afetos, memórias e identidades das comunidades com reflexo direto no grau de pertencimento que desenvolvem em relação ao equipamento. Estimulados os vínculos de identificação entre equipamento e comunidade, abre-se espaço para uma maior percepção de valor por parte de seus frequentadores. Além disso, criam-se condições mais favoráveis para derrubar eventuais interditos de natureza simbólica que dificultem apropriação entre equipamentos e frequentadores.

Vale a ressalva que os conceitos de democratização cultural e de democracia não precisam ser tratados como polos opostos e inconciliáveis. Conjugar ações que transitem entre os dois conceitos concorre para a criação de equipamentos multiculturais e articulados à promoção da diversidade cultural.

\section{Questão \#3}

Conforme exposto no caso, a abordagem territorializada da gestão de equipamentos gera impactos organizacionais, interorganizacionais e territoriais. Com base na leitura do caso e do artigo de Davel et al. (2016), identifique e discuta estas três ordens de impacto.

\section{Resposta possível}

0 estreitamento dos vínculos entre equipamento e território concorre para que o equipamento se diferencie, gere valor simbólico para suas ações e desperte nos seus diversos públicos de interesse a sensação de identificação e pertencimento (benefícios organizacionais). Também favorece o fortalecimento de ações de cooperação entre organizações que atuam no território (benefícios interorganizacionais), contribuindo para 0 fortalecimento do impacto cultural e social das ações empreendidas pelo grupo; a criação de soluções mais inovadoras para a resolução de problemas; 0 acesso a novas fontes de financiamento e o desenvolvimento de estratégias cooperadas de comunicação com maior impacto. Além disso, ganhos políticos (potencial de representação frente ao poder público e outros atores) e econômicos (fortalecimento da cadeia produtiva da cultura, do turismo e da economia local) podem ser acessados. Este processo impulsiona a construção de novas simbologias a respeito do próprio território, reconfigurando e reformulando sentidos que podem estar associados à valorização identitária, a processos de defesa e preservação do patrimônio artístico, cultural, humano e natural. Deste modo, pode contribuir com a qualificação das práticas de sociabilidade vigentes e fortalecer processos de construção da cidadania, bem como atuar como mola propulsora de novas oportunidades econômicas ao mobilizar produtos, serviços e experiências singulares (benefícios territoriais). 
Trata-se de uma abordagem que amplia a noção de sustentabilidade, englobando uma dimensão econômica (captação de recursos), política (ação junto a uma instância legal, institucional) e social (engajamento cidadão), num enforque sistêmico (ARMANI, 2001) que integra a dimensão gerencial de forma articulada com a dimensão sociopolítica da organização. 


\section{REFERÊNCIAS}

Alcaldía de Medellín. (2015). Días de Playa: Memórias, Laboratório Ciudadano y Participativo. Medellín: Alcaldía de Medellín.

Armani, D. (2001). O Desenvolvimento Institucional como Condição de Sustentabilidade nas ONG no Brasil. In Brasil. Ministerio da Saude. Aids e Sustentabilidade: Sobre as Ações das Organizações da Sociedade Civil (pp. 17-34). Brasília: Ministério da Saúde.

Botelho, I. (2001). Dimensões da Cultura e Políticas Públicas. Revista Perspectiva, São Paulo, 15(2), 73-83.

Bourdieu, P., \& Darbel, A. (2003). O Amor pela Arte: Os Museus de Arte na Europa e seu Público. São Paulo: Editora da Universidade de São Paulo.

Bravo, M. E. (2008). Políticas CulturalesenColombia. In Rubim, A. A. C.; Bayardo, R. (Orgs.). Políticas Culturais na Ibero América (pp. 119-137). Salvador: EDUFBA.

Canedo, D. P. (2007). Democratização da Cultura. In Ameida, M. C. F. (Org.). Mais Definições em Trânsito. Salvador: Edufba.

Castells, M. (1999). O Poder da Identidade: A Era da Informação (vol. 2). São Paulo: Paz e Terra.

Davel, E., Dantas, M., \& Santos, F. P. (2016). Identidade cultural de territórios como política de gestão. Anais do Encontro da ANPAD, Bahia, Costa do Sauipe.

De Marco, K. (2009). Gestão de Espaços Culturais: Uma Abordagem Contemporânea. In: Fonseca, A. C., \& De Marco, K. (Orgs.). Economia da Cultura: Ideias e Vivências (pp. 203-221). Rio de Janeiro: Ed. e-livre.

Echeverri, R. (2009). Identidade e Território no Brasil. Brasília: IICA.

Haesbaert, R. (2000). Dos Múltiplos Territórios à Multiterritorialidade. Anais do IX Encontro Nacional da ANPUR, Rio de Janeiro, 3.

Hall, S. (2014). Identidade Cultural na Pos-Modernidade. Rio de Janeiro: Lamparina.

Harvey, D. (2014). Condição Pós-moderna: Uma Pesquisa sobre as Origens da Mudança Cultural. São Paulo: Edições Loyola.

Lacerda, A. P. (2010). Democratização da Cultura x Democracia Cultural: os Pontos de Cultura Enquanto Política Cultural de Formação de Público. Anais do Seminário Internacional de Políticas Culturais: Teorias e Práticas. Rio de Janeiro, Fundação Casa de Rui Barbosa.

Melguizo, J. (2012). Parques-Biblioteca de Medellín: da Engenharia à Jardinagem Cultural. Anais do Seminário Internacional Cultura e Transformação Urbana, São Paulo, SESC São Paulo, Ed. Sesc SP.

Roser, B. (2009). Aprendiendo de Colombia: Cultura y Educación para Transformar laCiudad. Barcelona: FundaciónKreana.

Santos, M. (2000). O Papel Ativo da Geografia: Um Manifesto. Revista Território, 3(9), $103-109$.

Saquet, M. A.; Briskievicz, M. (2009). Territorialidade e Identidade: Um Patrimônio no Desenvolvimento Territorial. Caderno Prudentino de Geografia, 1(31), 3-16.

Saraiva, H. (2011). Gestão da Cultura e a Cultura da Gestão. In Barros, J. M.; Júnior, J. O. (Orgs.). Pensar e Agir comaCulturaDesafios da Gestão Cultural. BeloHorizonte: Observartório da Diversidade Cultural.

Saraiva, L. A., Carrieri, A. D. P. (2014). Territorialidade e IdentidadenasOrganizações: O Caso do Mercado Central de BeloHorizonte. Revista de Administração da Mackenzie, 15(2), 97-126. 